\title{
Investigating the Concept of Creative Disposition \& Decision Making Styles
}

\author{
Dr. SAYMA ZIA \\ Senior Associate Professor at Bahria University Karachi Campus. \\ Email: samhha1@ hotmail.com / saymazia.bukc@bahria.edu.pk \\ ISMAT FATIMA \\ MBA Scholar at Bahria University Karachi Campus.
}

SANA AZHER

Senior Lecturer, Bahria University Karachi Campus. Email: sanaazher.bukc@bahria.edu.pk

\begin{abstract}
This purpose of this study aims to determine the impact of decision making styles in organizations operating in Karachi. It focuses on exploring different components of decision making styles and investigates the concept of creative disposition. Moreover, it determines the correlation of different components of decision making styles to creative disposition of employees. It identifies necessary changes in decision making styles to increase its impact on creative disposition. Explanatory technique is adopted to determine the impact of logic, facts and personal experiences in decision making style on creative disposition; followed by primary data collection. Quantitative paradigms are used to perform the analysis. Target population of current study comprises of employees working in organizations of Karachi. Sampling technique used is non-probability convenient sampling. Sample size is of 384. Survey technique has been adopted for data collection process. Instrument used is questionnaire for data collection multiple linear regression technique has been used for analysis. The results of the study revealed that there is a significant role of logic based decision making style, facts based decision making style and personal experience based decision making style to determine positive creative disposition shows that it has a significant impact on it. This study successfully explained importance of decision making styles in developing creative disposition in organizations.
\end{abstract}

Keywords: Logic Based Decision Making Style, Facts Based Decision Making Style, Personal Experience Based Decision Making Style, Creative Disposition.

\section{Introduction}

Creative disposition has determined close association with personal attributes of an individual and is found to have a significant impact on decision making style (Gong, Huang \& Farh, 2009). Creative Disposition reveals modified approach to creativity that has found its evidences in industries with rapid changes (Lucas, Claxton \& Spence 2012). It has developed from psychological trait theory that concentrates on customary arrangements of human characters with variation from a traditional mindset (Wiliam, \& Black, 1996). Creative disposition addressed individual's abilities, attention, assertiveness and personality that have found close association in determination of decision making style followed (Treffinger, Young, Selby \& Shepardson, 2002).

Creative decision making style helps sub-ordinates to get knowledge from that decision and use it to develop their skills. It also help them to follow similar approach in their course of work which usually 
results in attaining work autonomy among employees that requires less close monitoring to them (Plucker $\&$ Makel, 2010). Education and experience has determined close association to determine decision making style and results an ultimate impact in determination of thinking process among employee that contribute to determine creative disputation attribute among them (Lucas \& Claxton, 2010). Individuals with creative decision making approach usually make them updated with relevant information to use them during decision making style Decision makers with creative disposition usually listen to other to cross check their level of information and awareness to ensure their attention to problem or issues confronted. They also use this information to guide them in decision making style (Steiner, 2006). Decision making approach also reveals level of openness among participants and its impact among team members to come up with unique conclusion (Hingel, 2009). Decision makers usually assess their alternative options with relevant information instead of only relying on its rationality. Furthermore, usually take valuable inputs to assess the reliability of their decision to reduce the risk associated with post decision scenarios (Heindel \& Furlong, 2000) Decision making style has found significant impact on organizational performance and specifically employees in service sector (Florida, 2002). It usually confronted with varying condition during their usually course of work therefore requires skills and capabilities to helps or assess them with good decision to resolved issued confronted (Fillis \& McAuley, 2000). In context of this research study information technology has an improved and widened scope in recent business environment therefore required with well-equipped human resource to contribution effectively in organizational development process (Feist, 2010). It has found that there is a significant scope of creative disposition of information technology industry. It determines concentration of creative mentality among employee within the industry. It determines success factor of IT firms (Csikszentmihalyi, 1996).

The scope of information technology has groomed with progress of time and has become an essential element of each business organization (Zhou \& George, 2003). The world has become at finger point of common person and it has squeezed within small electronic gadgets therefore exceptions of business segment of economy has increased toward IT professionals to come up with new ideas and thoughts to contribute their inputs in organizational development process (Zhao \& Seibert, 2006). In this context, IT firms usually come up with new requirement form business community to facilities with new tools and applications to atomize their operations procedure (Wong \& Law, 2002). It has now become essential to IT firms to groom their human resource factor that is an essential element of growth of IT firms and their sign of success and competitiveness (Wakefield, 2003).

IT firms usually focuses on selection of candidates with innovative ideas and ways of doing work to equip their human resource with quality worker to ensure maximum involvement in different projects to increase and expand their business (Weisberg, 1999). IT industry is usually found with demand of new hires with attractive offers (Weick, 1995). They are also invested with training and development opportunities specifically their decision making styles and way of working to increase their productivity (Sternberg, 2002). IT firms has come up with decentralized decision making approach with different small teams assigned with different projects (Rickards \& Moger, 2006).Team participants in IT industry are encouraged along with work autonomy to come up with suggestions and select a rational approach to perform their job assignment (Pan Sun \& Chow, 2012).

\section{Problem Statement}

Creative disposition has been determined as an essential factor to determine level of competency of IT firms. Decision making style also determines employee's attitude and organizational culture within an organization. It has also found significant impact on their creative disposition. There is significant scope of decision making style to mold creative disposition of employee and sub-ordinates to help them to adjust to work environment in an IT firm. Furthermore, decision making style determine different aspect of creative disposition of employee with necessary changes to follow the instruction and work as a team to attain team objectives. It has found that leadership attribute determine decision making style that has found significant contribution in determination of creative disposition of employees hence in this context, in this study the 
scope is focused to investigate the role of decision making style and necessary elements of decision making style in the organizations and its outcome on creative disposition of employees in IT firms.

\section{Objective of the Research}

The objectives of current research study are as follow:

- To understand the scope of decision making styles in IT firms operating in Karachi.

- To determine the impact of different components of decision making style to creative disposition of employee in IT firms operating in Karachi.

- To determine the requirement of necessary changes in decision making styles to increase its impact on creative disposition in IT firms of Karachi.

\section{Significance of the Research}

This research study has significant importance to different stakeholders and help different stakeholder in multiple ways to develop their understanding and level of information. This research study helps students of human resource management and management sciences to develop their understanding to scope of decision making style and its significant impact in determination of creative disposition among employee within IT firms operating in Karachi. It also gives them different idea to explore and develop their level of understanding. This study also provides research with new dimensions to explore their understanding to area of study and use it to conduct further in-depth studies enrich existing body of literature.

\section{Research Limitations}

The list of limitations associated with current research study is as follow:

- Time is determined as a major constraint to current research study and requires proper planning hence scope of study is designed keeping in consideration this aspect of present research study

- Financial factor has been determined as another constraint during the study, therefore, response collection process was limited to Karachi and certain number of IT firms were selected randomly to get desired number of responses using different options i.e. email, phone call and personal visits.

- Human resource factor is also determined as another factor to restrict number of responses collected hence it has considered as an important limitation during designing sample size.

\section{Literature Review}

\section{Bounded Rationality Model}

It has been explained through this model that human beings are limited in scope in comparison to the surrounding that is complex in nature hence decision makers have relatively limited level of information with less understanding to all possible alternatives to perform a task (Zahra \& Hitt, 2000). These results sometimes lapse to decide the optimal solution that results in decision making style but it has improved with selection of an appropriate one with availed level of information (Strack \& Deutsch, 2004). Decision making style helps to interlink operational goals of a business to its objective defined in strategies (Shepherd, McMullen, \& Ocasio, 2016). This decision making approach also guide to define sub goals in order to approach parent objective that results in gradual movement to ultimate destination (Smith \& Shefy, 2007). Furthermore, moving forward with sub-goals usually come up with additional information to assist in upcoming process to bring improvement (Powell, 2011). In addition, this approach also guide with 
involvement of individual with different specialties to contribute their inputs to help in comprehensive decision making style (Khatri \& Nig, 2000).

\section{Naturalistic Decision-Making Perspective}

In this approach experience has determined as an essential component of decision making style as prerequirement. It has significant contribution to enclose supportive information during decision making style and improve the quality of decision outcomes. It has further explained under this approach that decision making style does not follow random path but has a systematic base that enclose different factors more essential experience of participants during decision making style. It has further explained that decision making style is not a rigorous approach but usually follow systematic pattern in a gradual pattern. It has also explained through a study that contextual placement of problem confronted is essential to understand its causes and possible outcome to come up suitable solution to resolve the matter. In this approach, matters are discussed in situational perspective to come up with right solution. It has also revealed that an increased level of experience increase the probability of expected results with appropriate decision. Decision making style with a logical sequence and step wise assessment of condition confronted with possible available solution to determine rational one for resolution of problem confronted usually give high probability of success (Runco, 2010).

\section{Multiple Perspectives Approach}

In this approach each organizational problems has different perspective and nature therefore requires special attention to address the issue in light of its varying background to understand its essentials, inputs and its outcomes to think about it in different perspective using intellectual skills. It also helps to understand its different dimensions. Furthermore, this also helps to explore additional information and factual that comes up with supportive information in selection of appropriate solution handle the matter. Furthermore, it takes different angles to look into different organizational problems. It has also explained through a study that nature of problem not solely matter but its focuses on individual or actor taking in part in decision making style with supportive knowledge and experience to view its different dimension to come up with optimistic solution. In the context of this approach, it has emphasized that it is necessary to input different organizational resources, technical expertise and views of individual with different experience level within decision making style to come up with optimum solution

\section{Effect of Speed on Decision Making}

In this approach importance of additional supportive information has explored and its importance has highlighted to reveal that in comparison to traditional approach, modern approach i.e. effect of speed approach has significant advantages that it emphasizes on importance of collection of additional information to increase the consistency of decision making style and overcome the problems that has confronted as a result of uncertainty associated that result in an increase in risk associated with decision making style (Whittington, Timothy \& Galpin, 2010). It has also explained through this approach that additional information contributes to increase the level of information of participants in decision making style to increase awareness to problem or issue confronted to come with better solution to resolve the issue (Swaminathan \& Rajasekaran 2010). It has also explained through this study that uncertainties usually result in financial losses that although confronted with delay in additional information collection process reduce such financial losses their intensity. In contrast, it has revealed that higher the speed of decision is making process greater then efficiency of decision making style without unnecessary long delays. Decision making style reveals personality and way of thinking within organizational culture and helps to determine its psychological construct (Sternberg, 1996). 


\section{Decision Making Style and Creative Disposition}

Creative disposition addressed individual's abilities, attention, assertiveness and personality that have found close association in determination of decision making style followed (Treffinger, Young, Selby \& Shepardson, 2002). A significant number of studies have conducted to determine factors responsible for creative disposition in organizational practices and come up with significant contribution of decision making style in determination of this element (Gronhaug \& Haukedal, 1995). A significant change in decision making approach resulted in a significant shift way of thinking and welcomed innovative ideas to enhance human resource contribution in organizational development process (Hansen \& Crespell, 2008).

There is significant number of studies has conducted to determine the scope of decision making style in different industry within an economy but exploration of different aspect of decision making style that has resulted in an improvement in organizational performance and changing organizational culture (Hunter, Cassidy \& Ligon, 2011). It has developed from psychological trait theory that concentrates on customary arrangements of human characters with variation from a traditional mindset (Wiliam, \& Black, 1996). Creative deposition has determined has found close association with personal attributes of an individual and has found significant impaction on decision making style (Gong, Huang \& Farh, 2009). Creative Disposition reveals modified approach to creativity that has found its evidences in industries with rapid changes (Lucas, Claxton \& Spence 2012).

Creative decision making style helps sub-ordinates to get knowledge from that decision and use it to develop their skills. It also help them to follow similar approach in their course of work usually results in attaining work autonomy among employees that required less close monitoring to them (Plucker \& Makel, 2010). They less relies on their individual approach and do not think in isolation, take in consideration others views to come with concrete idea (Saltelli \& Villalba, 2008). Individuals with creative decision making approach usually make them updated with relevant information to use them during decision making style and come up with different ideas among others (Kaufman \& Sternberg, 2010). Education and experience has determined close association to determine decision making style and results an ultimate impact in determination of thinking process among employee that contribute to determine creative disputation attribute among them (Lucas \& Claxton, 2010).

\section{Logic Based Decision Making Style}

Decision making style with a logical sequence and step wise assessment of condition confronted with possible available solution to determine rational one for resolution of problem confronted usually give high probability of success (Runco, 2010). Logics in decision making style reveal personality and way of thinking within organizational culture and help to determine its psychological construct (Sternberg, 1996). Individuals with constructive logics has found with welcoming approach to apply creative disposition to capture relevant fact and consideration of relevant information during decision making style. It has also explained through this approach that additional information helps to construct logic correlation that contributes to increase the level of information of participants in decision making style to increase awareness to problem or issue confronted to come with better solution to resolve the issue (Swaminathan \& Rajasekaran 2010).

A significant number of studies have been conducted to determine logical factors that are responsible for creative disposition in organizational practices and come up with significant contribution of decision making style in determination of this element (Gronhaug \& Haukedal, 1995). There are significant number of studies conducted to determine the scope of logic in decision making style in different industries within an economy but exploration of different aspect of decision making style has resulted in an improvement in organizational performance and changing organizational culture (Hunter, Cassidy \& Ligon, 2011). A significant change in decision making approach with application of logics resulted in a significant shift way of thinking and welcomed innovative ideas to enhance human resource contribution in organizational development process (Hansen \& Crespell, 2008). 


\section{Fact Based Decision Making Style}

Facts help to understand ground level picture of existing disputes and area under attention. It helps to explore additional information and factual information that comes up with supportive information in selection of appropriate solution handle the matter. Furthermore, it takes different angles to look into different organizational problems (Sternberg, 1996). It has also explained through a study that nature of problem not solely matter but its focuses on individual or actor taking in part in decision making style with supportive knowledge and experience to view its different dimension to come up with optimistic solution. In the context of this approach, it has emphasized that it is necessary to input different organizational resources, technical expertise and views of individual with different experience level within decision making style to come up with optimum solution (Whittington, Timothy \& Galpin, 2010).

Individual decisions are usually overweighed on group or collective decision making style (Tamer, Bolat \& Yylmaz, 2009). It has explained through this study that group level decision usually confronted with delay and counter arguments that result in time delays while individual decision needs collection of necessary information, taking into account different facts and executing the decision (Baum \& Wally, 2003). Therefore decision making style include and observe organizational experience as valuable input during the process to make it factual (Druskut, Sala \& Mount, 2006). It leads to practical and realistic decisions (Allen, Dawson, Wheatley \& White, 2005). Decision making style has described as a systematic process that work mechanically and followed certain principle without any randomness (Antony \& Bhattacharyya, 2010).

\section{Personal Experience Based Decision Making Style}

Experience has found significant contribution determination of outcomes of decision making process. Decision making style is not an event but it bring at a point different participant along with experience within an organization to share their view, experience and idea to collectively come at a point to move forward operations of the organization. This gives right to each member of organization to counter argument their view and solution in light of other to come help senior management to decide one with optimal results. It results in filtration of different ideas, exclusion of unnecessary one and selection of appropriate one therefore it has pronounced as Garbage Can model. It has further explained in a view that it meeting of different organizational members at a point of time to decide a solution about confronted issues (Mayer, 2007).

Decision making style include and observe organizational experience as a valuable input during the process to make it factual and justified to business (Druskut, Sala \& Mount, 2006). It leads to practical and realistic decisions (Allen, Dawson, Wheatley \& White, 2005). Decision making style has described as a systematic process that work mechanically and followed certain principle without any randomness (Antony \& Bhattacharyya, 2010). A significant change in decision making approach resulted in a significant shift way of thinking and welcomed innovative ideas to enhance human resource contribution in organizational development process (Hansen \& Crespell, 2008).

\section{Research Questions}

The research questions of current study are as follow:

- What is the scope of decision making style in IT firms operating in Karachi?

- What is the marginal impact of different components of decision making style to creative disposition of employee in IT firms operating in Karachi?

- What are necessary changes necessary required in decision making style to increase its impact on creative disposition in IT firms of Karachi? 


\section{Theoretical Framework}

Creative disposition addressed individual's abilities, attention, assertiveness and personality that have found close association in determination of decision making style followed (Treffinger, Young, Selby \& Shepardson, 2002). A significant change in decision making approach resulted in a significant shift way of thinking and welcomed innovative ideas to enhance human resource contribution in organizational development process (Hansen \& Crespell, 2008). There is significant number of studies has conducted to determine the scope of decision making style in different industry within an economy but exploration of different aspect of decision making style that has resulted in an improvement in organizational performance and changing organizational culture (Hunter, Cassidy \& Ligon, 2011). Education and experience has determined close association to determine decision making style and results an ultimate impact in determination of thinking process among employee that contribute to determine creative disputation attribute among them (Lucas \& Claxton, 2010).

\section{Decision Making Style}

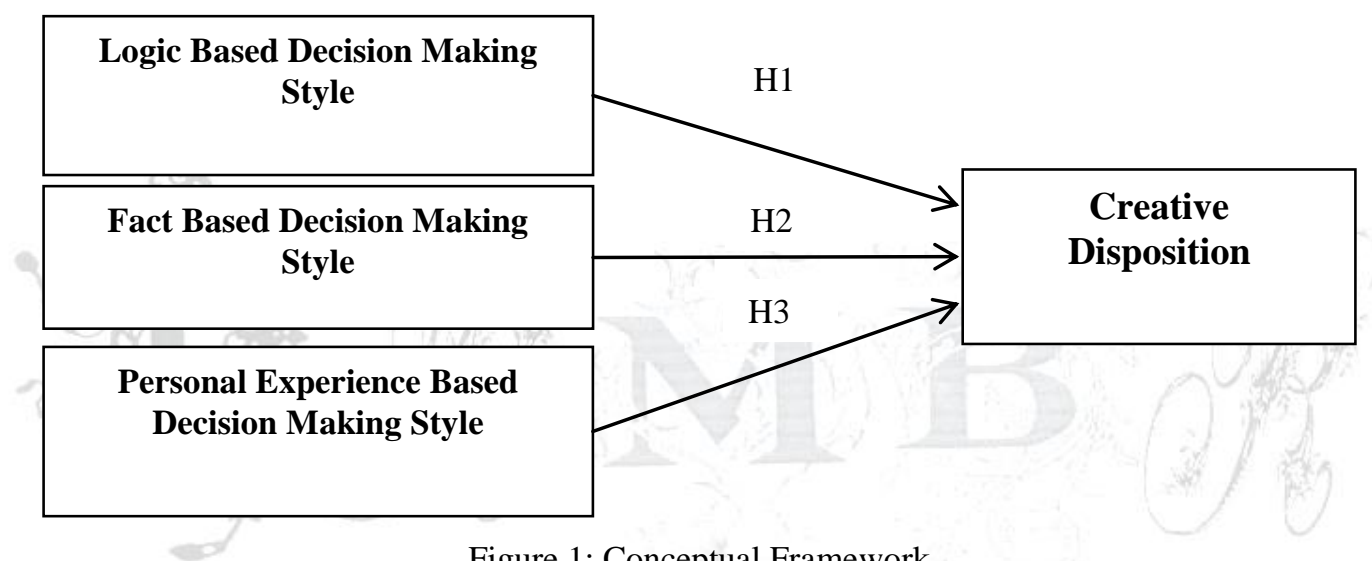

\section{Variables Studied}

Figure 1: Conceptual Framework

\section{Independent Variable}

Decision making style is the independent variable for this research; it has three sub-dimensions:

- Logic Based Decision Making Style

- Facts Based Decision Making Style

- Personal Experience Based Decision Making Style

\section{Dependent Variable}

Creative Disposition is the dependent variable of this research study.

\section{Hypotheses Deduced}

Following hypotheses are developed on the basis of independent and dependent variable: 
$\mathbf{H}_{\mathbf{a}} \mathbf{1}$ : There is a significant impact of logic based decision making style on creative disposition of employees in IT firms of Karachi.

$\mathbf{H}_{\mathbf{a}}$ 2: There is a significant impact of facts based decision making style on creative disposition of employee in IT firms of Karachi.

$\mathbf{H}_{\mathbf{a}}$ 3: There is a significant impact of personal experience based decision making style on creative disposition of employee in IT firms of Karachi.

\section{Research Methodology}

Deductive approach is used to deduce conclusions. The research employed the quantitative approach and therefore the data was collected through survey technique. Questionnaires were circulated to collect data from the respondents through different mediums. In this research study explanatory approach has been followed to determine the impact of logic, facts and personal experiences in decision making style on creative disposition of employees in IT firms of Karachi. This helps to determine the impact of independent variables on creative disposition of employees within IT firms of Karachi. It helps to identify most critical factors in decision making style with profound impact on creative disposition of employees and their relative importance in comparison to other factors. Likert scale is used that ranges from 1 to 5.1 stand for psychological response strongly disagrees while 5 stands for psychological response strongly agree. Disagree has nominated value 2, Neutral has nominated value 3 and Agreed has nominated value 4.Target population of the research comprises of employees working in organizations operating in Karachi city. In this context,IT firms working for more than 5 years within the city. Employees working in these firms belong to different geographic location within the city along with different demographic attributes to ensure their collective representation to the population.

This research study followed with non-probabilistic sampling technique. There is significant range of nonprobabilistic sampling technique amongst which convenience sampling technique has been selected to collect responses from target population.

The size of target population is not known and sample size is around 384 at 5 percent level of significance. So the sample size has been taken as 384 . This research study used questionnaire as data collection instrument which was adapted from (C.W. Allinson and J. Hayes,1996); S,.G. Scott and R.A. Bruce, 1995).

\section{Analysis}

\section{Reliability Test}

Cronbach's Alpha technique is used to test the reliability of the instrument. The bench mark value to read reliability of primary collected responses on this test scale is 0.6. If the value of test is equal to or greater than 0.6 then the response are considered as reliable.

Table No 1: Reliability Test Cronbach's Alpha or Section A: Logic Based DMS

\begin{tabular}{|lccc|}
\hline Construct & Items & Cronbach's Alpha & Internal Consistency \\
\hline Logic based decision making & 4 & $0.9>0.601 \geq 0.6$ & Acceptable \\
Fact based decision making & 4 & $0.9>0.6 \geq 0.6$ & Acceptable \\
Personal experience based & 4 & $0.9>0.671 \geq 0.6$ & Acceptable \\
Creative disposition & 5 & $0.9>0.629 \geq 0.6$ & Acceptable \\
\hline
\end{tabular}




\section{Interpretation}

The Cronbach's Alpha for logic based DMS, is 0.601which is greater than 0.6. This depicts that this factor is reliable. The value for Facts based DMS is 0.6 which is almost 0.6 therefore it is reliable and accepted. Furthermore, it is also evident from Cronbach's Alpha for personal experience based DMS is 0.671 i.e. greater than 0.6.and for creative disposition its 0.629 which is also greater than 0.6 and makes it reliable.

\section{Regression Model}

Table No 2: Model Summary for Regression Model

\begin{tabular}{|c|c|c|c|c|}
\hline Model & $\mathrm{R}$ & $\mathrm{R}$ Square & Adjusted R Square & Std. Error of the Estimate \\
\hline 1 & $.719^{\mathrm{a}}$ & .516 & .423 & .63366 \\
\hline
\end{tabular}

Predictors: (Constant), Personal Experience based Decision Making Style, Logic based Decision Making Style, Facts based Decision Making Style

\section{Interpretation of Model Summary}

Model Summary gives the R, R Square, Adjusted R Square and the standard error of the estimate. These values conclude how well a regression model fits the data. $R$ Square represents the value of 0.516 that shows $51.6 \%$ variation is explained by dependent variable (creative disposition) due to independent variables logic based DMS, facts based DMS, and personal experience based DMS.

Table No 3: ANOVA for Multivariate Regression Model

\begin{tabular}{|ll|c|c|c|c|c|}
\hline Model & & Sum of Squares & df & Mean Square & F & Sig. \\
\hline \multirow{3}{*}{1} & Regression & 113.981 & 3 & 37.994 & 94.625 & $.000^{\mathrm{b}}$ \\
& Residual & 152.578 & 380 & .402 & & \\
& Total & 266.560 & 383 & & & \\
\hline
\end{tabular}

a. Dependent Variable: Creative Disposition

b. Predictors: (Constant), Personal Experience based Decision Making Style, Logic based Decision Making Style, Facts based Decision Making Style

\section{Interpretation of ANOVA}

ANOVA table is divided in to two parts:

- Regression analysis

- Residual

The df stands for "degree of freedom" and F denotes the "Frequency".

ANOVA is used to compare differences of means among the two groups. The table shows that the independent variables are statistically significant to predict the dependent variable, $\mathrm{F}=94.625$ at the significance level of $0.000, \mathrm{p}<0.05$.The P-value in the ANOVA is less than .05 , the lower this value the more significant is the research model. It is clearly evident from the table mentioned above that this model is accepted as the P-value is .000, it can be stated that overall the model is significant and a good fit. 
Table No 4: Coefficient Matrix for Multivariate Regression Model

\begin{tabular}{|l|c|c|c|c|c|}
\hline \multirow{2}{*}{ Model } & \multicolumn{2}{|c|}{$\begin{array}{c}\text { Unstandardized } \\
\text { Coefficients }\end{array}$} & $\begin{array}{c}\text { Standardized } \\
\text { Coefficients }\end{array}$ & T & Sig. \\
\cline { 2 - 5 } & $\mathrm{B}$ & Std. Error & Beta & & \\
\hline (Constant) & .648 & .168 & & 3.853 & .000 \\
Logic based Decision Making Style & .131 & .046 & .130 & 2.848 & .005 \\
Facts based Decision Making Style & .120 & .046 & .122 & 2.599 & .010 \\
Personal Experience based Decision & .543 & .050 & .509 & 10.806 & .000 \\
Making Style & & & & & \\
\hline
\end{tabular}

a. Dependent Variable: Creative Disposition

\section{Interpretation of Coefficient Test}

According to our analysis ,the co-efficient table shows the "Sig" values in the last column which predicts us the significance of the variables and shows that whether variables are useful or not. It is clearly evident from coefficient matrix table that there is significant role of logic based decision making style, facts based decision making style and personal experience based decision making style in determination of creative disposition among employees in IT firms of Karachi. In case of first variable i.e. Logic based Decision Making Style, the $\mathrm{p}$ value is 0.005 which is less than 0.05 ; it means this variable is useful and it shows that there is a positive impact of logic based DMS on creative disposition in IT firms of Karachi. The p value of second independent variable "Facts based decision making style" is 0.010 which is less than 0.05 ; that means this variable is a useful variable and it creates positive impact on creative disposition. The $p$ value of third independent variable "Personal Experience based Decision Making Style" is 0.000 which is less than 0.05 that means this variable is useful and it creates positive impact on employee satisfaction. The coefficient value of logic based decision making style, facts based decision making style and personal experience based decision making style are $0.131,0.120$ and 0.543 respectively. Hence, the equation can be formed as:

$\mathrm{y}=\mathrm{a}+\mathrm{b}_{1} \mathrm{x}_{1}+\mathrm{b}_{2} \mathrm{x}_{2}+\mathrm{b}_{3} \mathrm{x}_{3}+\mathrm{e}$

$\mathrm{y}=0.648+0.131(\mathrm{LD})+0.120(\mathrm{FD})+0.543(\mathrm{PD})+\mathrm{e}$

\section{Hypotheses Assessment Summary}

This research study clearly revealed that there is a significant role of logic based decision making style, facts based decision making style and personal experience based decision making style in determining the creative disposition among employees in IT firms of Karachi. Logic based decision making style, facts based decision making style and personal experience based decision making style determine positive creative disposition and is found to have a significant impact on it. It is further summarized in the table below:

\section{Discussion}

The following chapter discusses the findings of the current study in the light of previous studies.

\section{Logic based Decision Making Style and Creative Disposition}

In case of first variable i.e. Logic based Decision Making Style, the p value is $\mathbf{0 . 0 0 5}$ which is less than 0.05; it means this variable is useful and it shows that there is a positive impact of logic based DMS on creative disposition in IT firms of Karachi. 
According to Runco (2010), decision making style with a logical sequence and step wise assessment of condition confronted with possible available solution to determine rational one for resolution of problem confronted usually give high probability of success. It is clearly evident from current research study that there is significant scope of logic based decision making style. It determines essentiality of decision making style and its usefulness to different participants involved in decision making style. Furthermore, it determines the outcome of decision making style to the organization. It helps in logical assessment of the problems or issues addressed during decision making style and its resultant impact on employee attribute that is reflected through their creative disposition.

Individuals with creative disposition has found with welcoming approach to relevant facts and consideration of relevant information during decision making style. They rely less on their individual approach and do not think in isolation. They take others views in consideration to come up with concrete idea (Saltelli \& Villalba, 2008). Decision making style reveals personality and way of thinking within organizational culture and helps to determine its psychological construct (Sternberg, 1996). Creative decision making style helps sub-ordinates to get knowledge from that decision and use it to develop their skills. It also help them to follow similar approach in their course of work which usually results in attaining work autonomy among employees that required less close monitoring to them.

\section{Facts based Decision Making Style and Creative Disposition}

The $\mathrm{p}$ value of second independent variable "Facts based decision making style" is $\mathbf{0 . 0 1 0}$ which is less than 0.05 ; that means this variable is a useful variable and it creates positive impact on creative disposition. It is also evident from the research that there is significant importance of relevant facts during decision making style and it determines usefulness of decision making style to the organization. It has also been found that the relevant facts results in an improvement in success factors of decision with change in operational method that come up with change in way of doing work and general attribute of worker within IT firms.

It has further explained that decision making style is not a rigorous approach (Hart, 2008). According to Crespell, P., \& Hansen , E. (2008), contextual placement of problem confronted is essential to understand its causes and possible outcome to come up suitable solution to resolve the matter. In this approach, matters are discussed in situational perspective to come up with right solution. It has also revealed that an increased level of experience increase the probability of expected results with appropriate decision.

\section{Personal Experience based Decision Making Style and Creative Disposition}

The $\mathrm{p}$ value of third independent variable "Personal Experience based Decision Making Style" is 0.000 which is less than 0.05 that means this variable is useful and it creates positive impact on employee satisfaction.

According to Csikszentmihalyi, M. (1996), it takes different angles to look into different organizational problems. It has also been explained through a study that nature of problem does not solely matters. Rather it focuses on individual using the decision making style with supportive knowledge and experience to view its different dimension to come up with optimistic solution (Feist, E., \& Primis, H., 2010). In the context of this approach, it has emphasized that it is necessary to input different organizational resources, technical expertise and views of individual with different experience level in decision making style to come up with optimum solution. It is also evident through the research that personal experience has significant contribution in determination of quality of decision and their probability of success necessary to input from individuals in decision making. Furthermore, this increases the understanding and awareness to ground realties that helps come with an appropriate solution during decision making that support the confidence level of different stakeholder. 
Different perspective and nature therefore requires special attention to address the issue in light of its varying background to understand its essentials, inputs and its outcomes to think about it in different perspective using intellectual skills (Gronhaug, K., Ingeborg, A. K., \& Haukedal, W., 1995). It also helps to understand its different dimensions. Furthermore, this also helps to explore additional information and facts that come up with supportive information in selection of appropriate solution handle the matter.

This research study is performed with an aim to determine the scope of decision making style in IT firms operating in Karachi to explore different components of decision making style. It is also focused to investigate the concept of creative disposition and determine the correlation of different components of decision making style to creative disposition of employees in IT firms operating in Karachi. It emphasizes on coming up with necessary changes in decision making style to increase its impact on creative disposition in IT firms of Karachi.

The marginal impact of logic, facts and personal experience in decision making style is $0.131,0.120$ and 0.543 respectively. It clearly indicates that there is relatively more significant role of personal experience in decision making style in comparison to other variables.

\section{Conclusion}

The conclusion drawn for the research is based on the value findings of this research and is as follows:

- It is necessary to train the employees in personal experience based decision making styles in IT firms operating in Karachi that support the firms in IT industry and bring significant impact in improving creative disposition.

- It is also required to consider facts during decision making style. It makes it more concrete and precise which is the essentiality of decision making style and reflects its importance to the origination

- It is also needed to ensure role of personal experience during decision making style to input past experiences during decision making within the current decision and its future impact on the organization.

- It is also required to ensure appropriate mix of logic, facts and personal experience in decision making style to ensure output through decision making process.

- It is required to develop tool to monitor influence of decision making style on creative disposition of employees in organizational structure to determine appropriate path of decision making.

\section{References}

Crespell, P., \& Hansen , E. (2008). Work climate, innovativeness, and firm performance in the US forest sector: In search of conceptual framework. Canadian Journal for Forest Research, 1703-1715.

Csikszentmihalyi, M. (1996). Creativity: The work and lives of 91 eminent people. Boston: McGrawHill.

Feist, E., \& Primis, H. (2010). Psycology: Making Connections. Boston: McGraw Hill.

Gong, Y., Huang, J. C., \& Farh, J. L. (2009). Employee learning orientation, partcipation in deicsion making, and employee creativity: The mediating role of employee creative self-efficacy. Academy of management Journal, 765-778.

Gronhaug, K., Ingeborg, A. K., \& Haukedal, W. (1995). Observation of a Strategic Employee Decision. Psychology \& Marketing, 239-253.

Hart, H., Grigorenko, E. L., \& Sternberg, R. J. (2008). Critical issues and practices in decision making process. Journal of Human Practices, 43-54.

Heindel, C., \& Furlong, L. (2000). Philosophies of Creativity: Two Views. Journal of Psychology, 47-52.

Lucas, B., \& Claxton, H. (2010). A Five-Dimensional Model of Creativity and its Assessment. Applied Measurement in Education, 278-290. 
Lucas, B., Claxton, G., \& Spencer, E. (2013). Expansive education: Teaching learners for the real world. New York: Open University Press.

Runco, L. (2010). Creativity and Ethics: The Relationship of Creative and Ethical Problem-Solving. Creativity Research Journal, 74-89.

Saltelli, A., \& Villalba, E. (2008). How About Composite Indicators: Measuring Creativity. Journal of Human Resource Management, 17-24.

Sternberg, J. R. (1996). Cognitive Psychology. Harcourt Brace College Publishers.

Sternberg, R. J., \& Kaufman, L. (2010). The Nature of Creativity. Creativity Research Journa, 87-98.

Treffinger, D. J., Young , G. C., Selby , E. C., \& Shepardson, C. A. (2002). Assessing creativity: A technical guide. Connecticut: National Research Center on the Gifted and Talented, University of Connecticut.
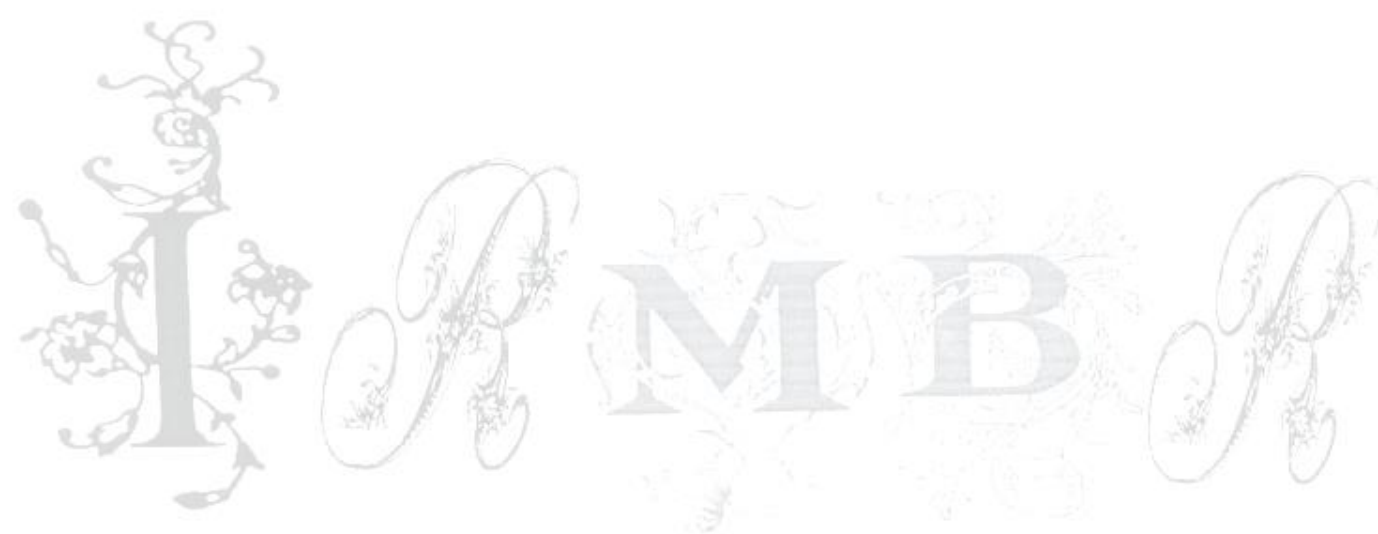


\section{Appendix}

\section{Questionnaire}

\begin{tabular}{|c|c|c|c|c|}
\hline Gender & Male & & \multicolumn{2}{|l|}{ Female } \\
\hline Education & Undergra & L & Graduate & Postgraduate \\
\hline Age Group & $22-30$ & & $31-40$ & $>40$ \\
\hline Years of Experience & $<5$ & $6-10$ & $11-20$ & $>20$ \\
\hline
\end{tabular}

a. Kindly answer the following question and check $\checkmark$ the appropriate box.

b. Choices are defined as: (1) Strongly Disagree (SD), (2) Disagree (DA), (3) Neutral (N), (4) Agree (A), (5) Strongly Agree (SA)

\begin{tabular}{|c|c|c|c|c|c|c|}
\hline & & $\begin{array}{l}\text { SD } \\
\text { (1) }\end{array}$ & $\begin{array}{l}\text { D } \\
\text { (2) }\end{array}$ & $\begin{array}{l}\mathbf{N} \\
\text { (3) }\end{array}$ & $\begin{array}{l}\text { A } \\
\text { (4) }\end{array}$ & $\begin{array}{l}\text { SA } \\
\text { (5) }\end{array}$ \\
\hline & \multicolumn{6}{|l|}{ Section A: Logic Based Decision Making Style } \\
\hline A1 & I feel more comfortable making decisions in a logical way. & & & & & \\
\hline A2 & I feel more comfortable making decisions in a systematic way. & & & & & \\
\hline A3 & $\begin{array}{l}\text { I usually interlink available information with issue confronted to } \\
\text { come up with right solution. }\end{array}$ & & & & & \\
\hline A4 & $\begin{array}{l}\text { I interlink different operational aspects to come up with concrete } \\
\text { decision. }\end{array}$ & & & & & \\
\hline & \multicolumn{6}{|l|}{ Section B: Facts Based Decision Making Style } \\
\hline B1 & I make decisions more on facts than my gut instincts. & & & & 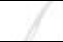 & \\
\hline B2 & $\begin{array}{l}\text { My decision making tends to involve careful analysis of facts and } \\
\text { weighting of decision criteria. }\end{array}$ & & & & & \\
\hline B3 & $\begin{array}{l}\text { The best decisions I make are based on detailed analysis of factual } \\
\text { information. }\end{array}$ & & & & & \\
\hline B4 & $\begin{array}{l}\text { I also search for additional information to support the decision } \\
\text { making style }\end{array}$ & & & & & \\
\hline & \multicolumn{6}{|l|}{ Section C: Personal Experience Based Decision Making Style } \\
\hline $\mathrm{C} 1$ & $\begin{array}{l}\text { When making decisions, I rely upon my intuition more than } \\
\text { anything else }\end{array}$ & & & & & \\
\hline $\mathrm{C} 2$ & $\begin{array}{l}\text { When I make decisions, it is more important for me to feel that the } \\
\text { decision is right, than to have a rational reason for it. }\end{array}$ & & & & & \\
\hline $\mathrm{C} 3$ & $\begin{array}{l}\text { I will not make a choice that does not feel right even when the facts } \\
\text { indicate it is the right choice. }\end{array}$ & & & & & \\
\hline $\mathrm{C} 4$ & When I make decision, I trust my inner feelings and reactions. & & & & & \\
\hline & Section D: Creative Disposition & & & & & \\
\hline D1 & $\begin{array}{l}\text { Logical ground in decision making comes up with decisions that } \\
\text { has positive impact on organizational performance. }\end{array}$ & & & & & \\
\hline $\mathrm{D} 2$ & $\begin{array}{l}\text { Selection of relevant facts and additional information results in } \\
\text { selection of most appropriate solution. }\end{array}$ & & & & & \\
\hline D3 & $\begin{array}{l}\text { Inputting personal experience during decision making improves } \\
\text { results. }\end{array}$ & & & & & \\
\hline D4 & $\begin{array}{l}\text { Detailed analysis prior to decision making makes decision more } \\
\text { concrete and successful. }\end{array}$ & & & & & \\
\hline
\end{tabular}

